\title{
La valoración del agua desde la diversidad cultural
}

Los pueblos originarios tienen formas colectivas ancestrales de gestionar sus aguas de acuerdo con sus cosmovisiones.

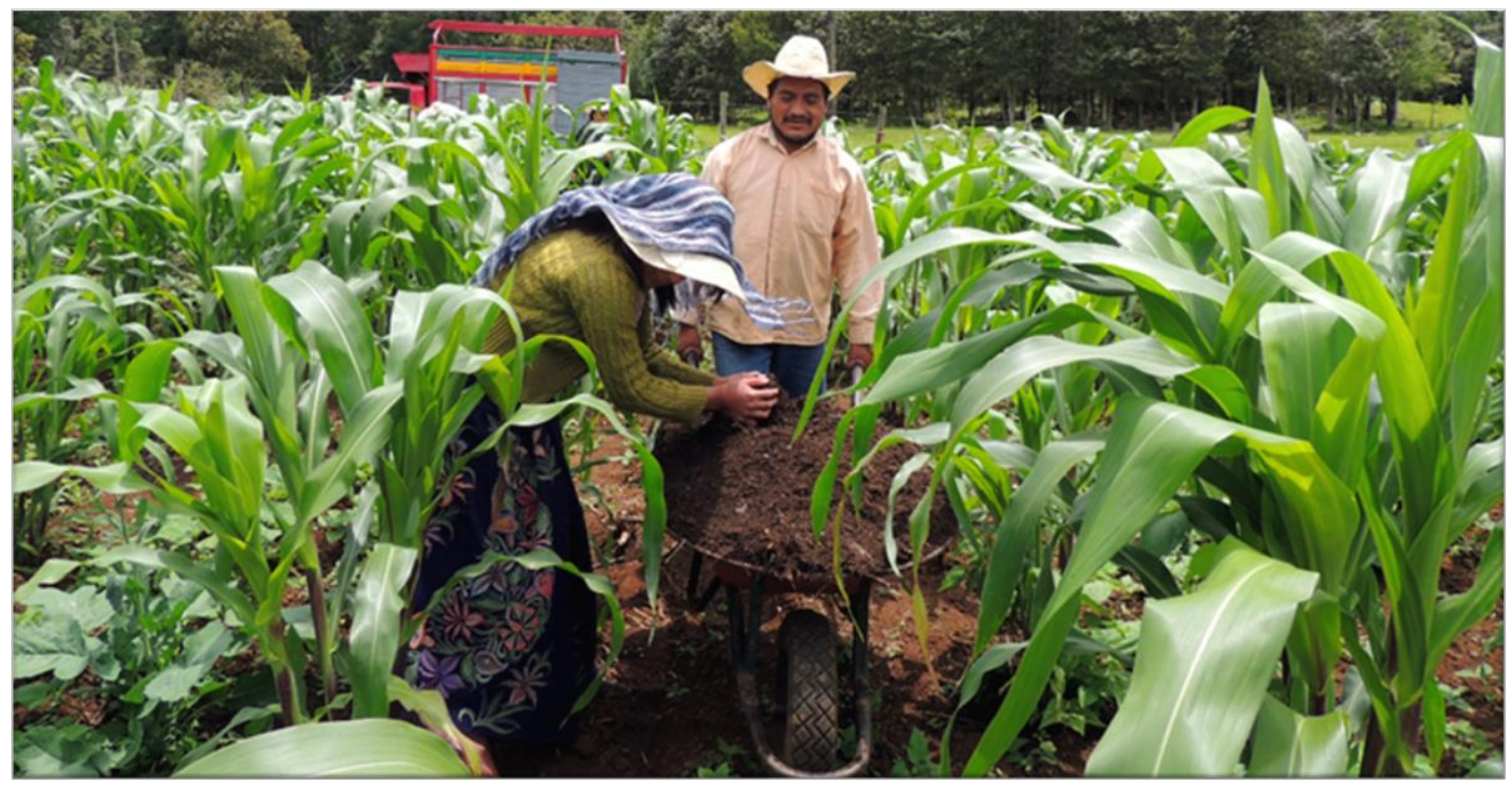

La Organización de las Naciones Unidas nos ha convocado desde el 22 de marzo de 1993 a celebrar anualmente el Día Mundial del Agua, que visibiliza el objetivo de desarrollo sostenible de garantizar para el año 2030 el agua y el saneamiento para todos.

En 2021, el lema de esta fecha conmemorativa es "Valoremos el agua", pero su valoración requiere de la construcción de un sistema de enfoques comunes entre múltiples escalas de valores, algunas de ellas no cuantificables, y que condensan disensos entre actores sociales y al interior de los mismos. Por lo tanto, este tema puede ayudarnos a avanzar hacia un acceso equitativo y justo al elemento hídrico, en el que ejerzamos el reconocimiento de la diversidad que somos los mexicanos y mexicanas.

La valoración del agua implica múltiples dimensiones. En primera instancia está el agua para la vida, es decir, el agua como derecho humano; la necesidad de que todos tengamos un abastecimiento de agua diario en el hogar para uso personal, alimentación e higiene. En este punto, el Gobierno mexicano está haciendo esfuerzos para ampliar la cobertura del servicio y adaptarlo a las necesidades locales de agua e infraestructura; sin embargo, se deben redoblar esfuerzos en los sectores más marginados, que resultan afectados por esta carencia estructural. 
Otra dimensión de valoración es la económica, en la que el agua es principalmente un recurso o materia prima de actividades extractivistas, cuyo manejo ha ocasionado su sobreexplotación y contaminación para favorecer la producción industrial de comida, ropa, tecnologías etc. en los mercados nacional e internacional. Por las cantidades extraídas y la escasa atención en el ciclo hidrosocial, el impacto en la disminución y contaminación de acuíferos es notorio. Al respecto, en la declaración del Alto Comisionado de las Naciones Unidas para los Derechos Humanos se sugiere que estas aguas deberían gestionarse en un segundo nivel de prioridad?.

Otras perspectivas destacan el valor de las infraestructuras hidráulicas y la oportunidad que ofrecen de abastecer agua en lugares donde no la hay. Estas contrastan con aquellas que subrayan la importancia ecológica de una fuente de agua natural, su valor como regulador térmico, como hábitat de especies endémicas o desde su unicidad biológica, que justifican formas de protección y resguardo del bien.

Cuando habitamos contextos urbanos concebimos el agua separada de su entorno natural, pero las poblaciones que habitan el México rural, que son aproximadamente el 21 \% de los mexicanos, según el Inegi (2020), valoran el agua de acuerdo con sus cosmovisiones, no comprendiéndola separada de sí mismas ni de otros elementos de la naturaleza, sino en una concepción relacional del territorio. Es así como existe una valoración del agua desde las cosmovisiones y formas de vida de las poblaciones indígenas y campesinas de nuestro país. En esta perspectiva se ha manifestado la negativa a considerar el agua y otros elementos de la naturaleza como recursos; por el contrario, se destaca su importancia como bienes comunes al haber organizaciones locales para gestionar y abastecerse del elemento hídrico. Desde este enfoque, el agua se valora por ser necesitada en forma transgeneracional, por ser heredada de forma colectiva y resguardada de la misma manera. Aunque es recurrente que existan conflictos entre las comunidades, también suele lograrse que el agua llegue a todos los usuarios de formas más o menos equitativas, según el caso.

Los pueblos originarios tienen formas colectivas ancestrales de gestionar sus aguas de acuerdo con sus cosmovisiones. En los casos de los tsotsiles y tseltales de los Altos de Chiapas, existe una convicción de que el mundo físico en que habitan es una herencia de siete generaciones atrás y a la vez es un legado para siete generaciones adelante de ellos. Esta apropiación de una temporalidad de largo plazo para una generación presente implica una responsabilidad expandida por las decisiones que se tomen sobre el territorio, el agua y otros elementos de la naturaleza.

Paralelamente, una singularidad de las lenguas mayas al nombrar el agua es que no se puede referir a ella en primera persona con un pronombre posesivo; puede decirse quién utilizó el agua, pero nunca significará que le pertenezca. Este detalle lingüístico es una evidencia del arraigo en la cosmovisión del elemento hídrico como bien común. También se relaciona con la condición numinosa del agua, porque ella se pertenece a sí misma y a las entidades sagradas que la habitan, aunque sea utilizada por algunos. Para comprender este punto partiremos de las cosmovisiones de los pueblos originarios sobre el agua que forman parte de un complejo prehispánico montaña-cueva-agua, en el cual, como expresa la etnóloga Johana Broda, las deidades del México antiguo subsisten reinterpretadas y sincretizadas en elementos prominentes del paisaje, como los cerros, las cuevas, las cascadas, las lagunas o los ríos. Esta herencia se manifiesta actualmente en que las fuentes de agua suelen tener un guardián, un dueño, un cuidador que sería una entidad sagrada, normalmente una reminiscencia de las deidades prehispánicas con advocaciones en las cosmovisiones ancestrales y en el santoral católico sincretizado. Esto lleva a que una fuente de agua puede tener el mismo fervor y devoción de la virgen María, quien en muchas ocasiones la encarna. 
En este sentido, para los pueblos originarios cada fuente de agua es única e irremplazable, cada una tiene un significado y se integra con otros lugares del paisaje; por ejemplo, estableciendo redes de familias como partes de un organismo antropomorfo natural-cultural regional. La historia oral da cuenta de estos vínculos de centros numinosos y de cómo la existencia de unos depende de los otros.

Todos estos elementos en los que pervive un culto ancestral a las deidades del agua están íntimamente relacionados con el cultivo de la milpa, tecnología agrícola mesoamericana que contiene una asociación de especies como el maíz, el frijol, la calabaza y el chile, entre otros, que intercambian nutrientes y se benefician mutuamente para su crecimiento y control de plagas. La milpa es una parte esencial de la agricultura de temporal, conocida también como de secano, y se caracteriza por depender del ciclo de Iluvias y secas. Este ciclo no puede separarse del ciclo del maíz, ni desvincularse del ciclo ritual anual expresado generalmente en el santoral católico, porque todo el trabajo anual de hombres y mujeres que subsisten en esta práctica agrícola está determinado por la expectativa en la llegada de las Iluvias y en su disponibilidad suficiente. En este sentido pervive la relación con la tierra, la luna y el agua como "Madres de los mantenimientos", entidades sagradas femeninas que a través del trabajo de la agricultura dan la abundancia que sustenta la vida de los pueblos.

Fenómenos como el cambio climático, la falta y el exceso de agua que cada vez son más notorios, la erosión de los suelos, el impacto negativo de los agroquímicos, entre muchos otros, han afectado la producción de las milpas. En este punto es necesario continuar trabajando para que haya una distribución más equitativa de las tecnologías que permiten un acceso al agua para la agricultura de forma más amplia, buscando beneficiar a los pequeños y medianos propietarios.

Debemos tener presente que la riqueza de las cosmovisiones de México no resuelve del todo problemáticas relacionadas con la conservación del agua. Es necesario que las organizaciones comunitarias para la gestión y protección de los elementos de la naturaleza continúen promoviendo el diálogo y la transformación de prácticas que deterioran el medio ambiente, como son el abandono de las cañadas como basureros y depósitos de aguas residuales o la deforestación.

Complementariamente, aunque es un reto, es importante que las instituciones del Estado avancemos en el reconocimiento de las diversidades de la nación para fortalecer procesos más adecuados a los contextos y las culturas. En este punto debemos esforzarnos para superar la herencia del despojo material y simbólico de las fuentes de agua. Cuando las decisiones se toman desconociendo las concepciones que las comunidades tienen del agua y son impuestas a los pueblos, se repite una dinámica que vulnera el derecho a la autodeterminación de los pueblos, a ser diferentes y a tomar decisiones siguiendo valoraciones distintas a las hegemónicas.

Finalmente, queremos subrayar el valor del agua como punto de encuentro, ya que, junto a pozos y caudales siempre están las poblaciones, se cruzan los viajeros, se celebran los rituales y se buscan las formas de distribuir la vida entre diferentes usuarios, territorios, culturas. Este año, en el agua nos encontramos para hablar de la valoración, del reconocimiento y respeto de la diversidad, de la necesidad de establecer prioridades y límites en cuanto a la forma de valorar el agua, porque es un recurso finitovital con el que podremos ejercer justicia con las comunidades que han sido despojadas de sus aguas, de los significados que estas guardaban, que han quedado con sus fuentes contaminadas o con aquellas que no tienen agua en sus territorios. 
PERSPECTIVAS IMTA (0)

$N^{\circ} .11,2021$

Autora: Natalia Chaves López

DOI: doi.org/10.24850/b-imta-perspectivas-2021-11 